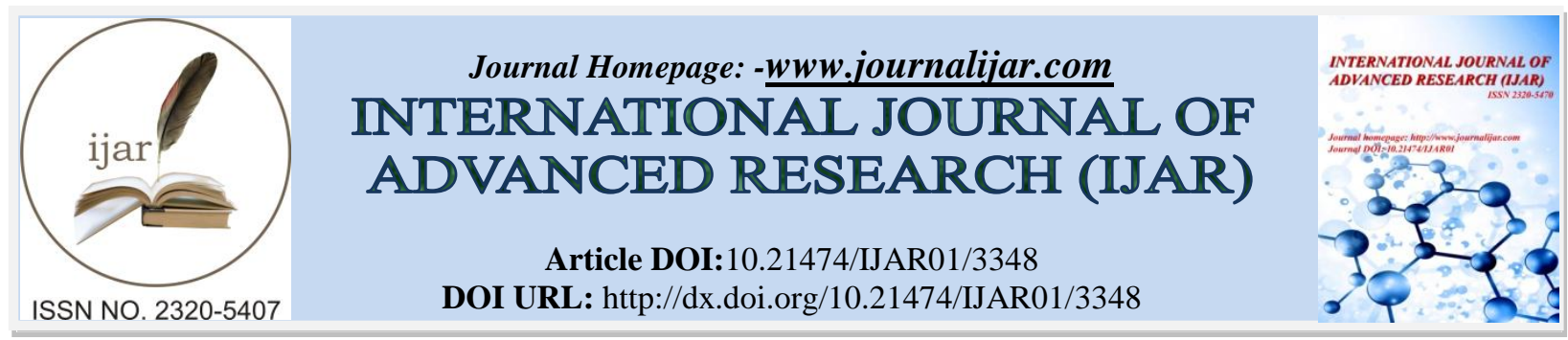

RESEARCH ARTICLE

\title{
SEISMIC ANALYSIS OF RC ELEVATED RECTANGULAR WATER TANK USING IS 1893 (PART2):2006 DRAFT CODE
}

Sayed Habiburahman Haqbin ${ }^{1}$, Chintan.D.Patel ${ }^{2}$ and Bansal. R. Patel ${ }^{2}$.

1. P.G Student Applied Mechanic Department, LDCE, Ahmedabad.

2. Assistant Professor Applied Mechanics Department, LDCE, Ahmedabad.

\section{Manuscript Info}

Manuscript History

Received: 25 December 2016

Final Accepted: 22 January 2017

Published: February 2017

Key words:-

Spring Mass Model, Staging Height, Seismic Zones, Excel Sheet and STAAD.pro

\begin{abstract}
The tank is considered two degrees of freedom system with a large mass is located at the top of supported system or frame supported system. The behavior of tank under earthquake loading is greatly depending on the staging height and seismic zones. And also seismic forces dependent on staging height. Present studying is shown the effect of staging height on seismic behavior of R.C elevated rectangular water tank. The elevated water tank has $300 \mathrm{~m}^{3}$ capacity, various staging height such as $(6 \mathrm{~m}, 9 \mathrm{~m}, 12 \mathrm{~m}, 15 \mathrm{~m}, 18 \mathrm{~m}$ and $21 \mathrm{~m})$ and also different seismic zones such as II, III, IV \& V were studied in STAAD.pro analysis package and Excel sheet developed program. The spring mass model subjected two degrees of freedom as per IS 1893 (part2):2006 draft code. Analysis carried out by considering the liquid mass is divided into two parts consisting of the convective and impulsive masses. Parameter of studying such as maximum displacement, maximum base shear, maximum overturning moment,quantity of concrete and amount of reinforcement for different staging height and seismic zones.in the case of studying for finding out maximum base shear and overturning momentby using Excel sheet and maximum displacement, quantity of concrete and quantity of reinforcement with STAAD.pro analysis package were used and the result of the studying were plotted in the graphs.
\end{abstract}

Copy Right, IJAR, 2017,. All rights reserved.

\section{Introduction:-}

Water tank is an important and strategic structure and it should remain functional during earthquakes to overcome the water demand due to fire etc. Water tanks are different from the building, because the huge mass of water is located at the top of supporting system. During the earthquake the mass of water is considered two parts such as impulsive and convective liquid mass. The good understanding of the behavior of water tank during seismic activity is necessary in order to evaluate the forces exerted due to earthquake and response of water tank.in the case of elevated water tank resistance against earthquake force is largely dependent of the supporting system. Staging of the elevated water tank is considered to be the critical element subjected to the lateral forces (seismic forces).when the tank partially filled with water, the tank is subjected to horizontal seismic acceleration and sloshing waves generates which exerts hydrodynamic forces on wall and the base of water tank.to calculate these hydrodynamic forces spring mass model suggested as per IS 1893(part2) :2006 draft code can be used.in the case of water tank, behavior of tank 
under hydrodynamic and hydrostatic forces are considered is greatly dependent on the configuration of staging its height and stiffness.

\section{Methodology:-}

In the present studying different staging height and seismic zones was considered for the same capacity of water and configuration of tank. The R.C elevated rectangular tank is selected with $300 \mathrm{~m}^{3}$ capacity and analysis in the II, III, IV\&V seismic zones. Tank is analyzed by using Excel sheet developed program and STAAD.pro analysis package and performance with respect to maximum base shear, maximum overturning moment ,maximum displacement, quantity of concrete and quantity of steel are presented. Six different staging heights are considered for studying such as $6 \mathrm{~m}, 9 \mathrm{~m}, 12 \mathrm{~m}, 15 \mathrm{~m}, 18 \mathrm{~m}$ and $21 \mathrm{~m}$. The foundation depths are kept same for finding out the effect of staging height on seismic behavior of elevated water tank.

Table.1:-Analysis Data

\begin{tabular}{|c|c|}
\hline Soil type & Medium \\
\hline Importance factor & 1.5 \\
\hline Response reduction factor for SMRF & 2.5 \\
\hline Seismic zones & II,III,IV \&V \\
\hline Size of columns & $1.0 \mathrm{~m} * 0.8 \mathrm{~m}$ \\
\hline Size of tie beam & $0.8 \mathrm{~m} * 0.5 \mathrm{~m}$ \\
\hline Height of staging & $6 \mathrm{~m}, 9 \mathrm{~m}, 12 \mathrm{~m}, 15 \mathrm{~m}, 18 \mathrm{~m} \& 21 \mathrm{~m}$ \\
\hline Depth of foundation & $1.5 \mathrm{~m}$ \\
\hline Thickness of wall & $0.32 \mathrm{~m}$ \\
\hline Thickness of base slab & $0.32 \mathrm{~m}$ \\
\hline
\end{tabular}

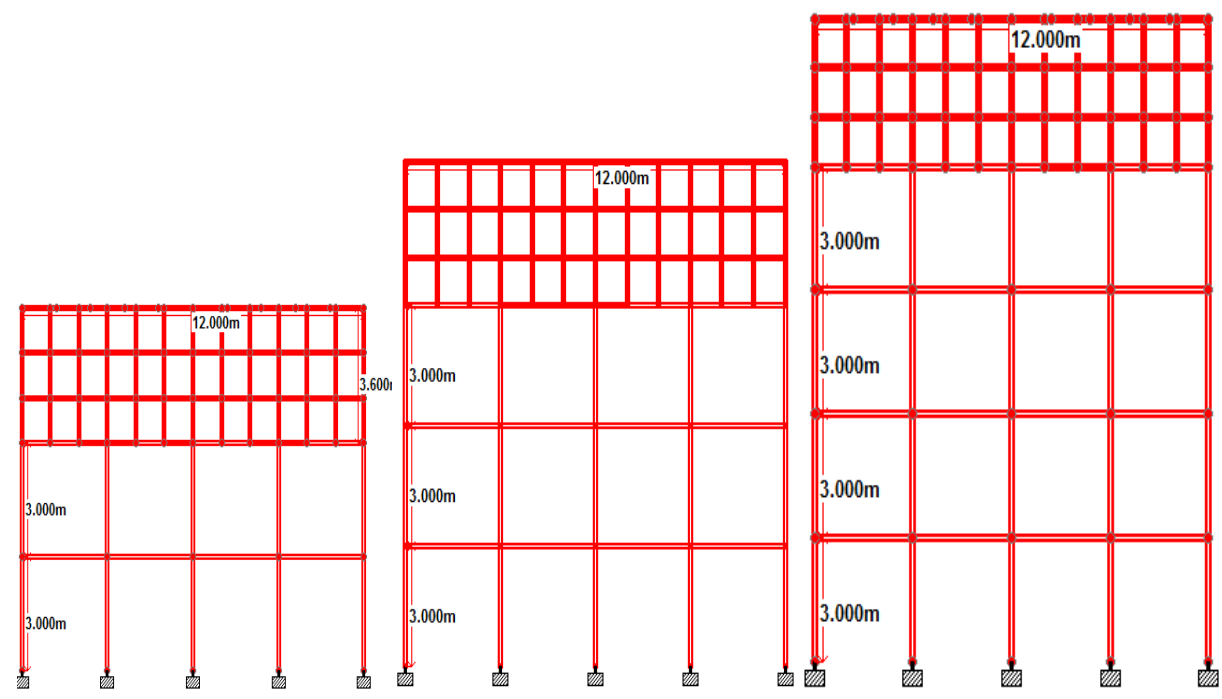

Fig. 1:-Elevation of Different Staging Height of Water Tank 


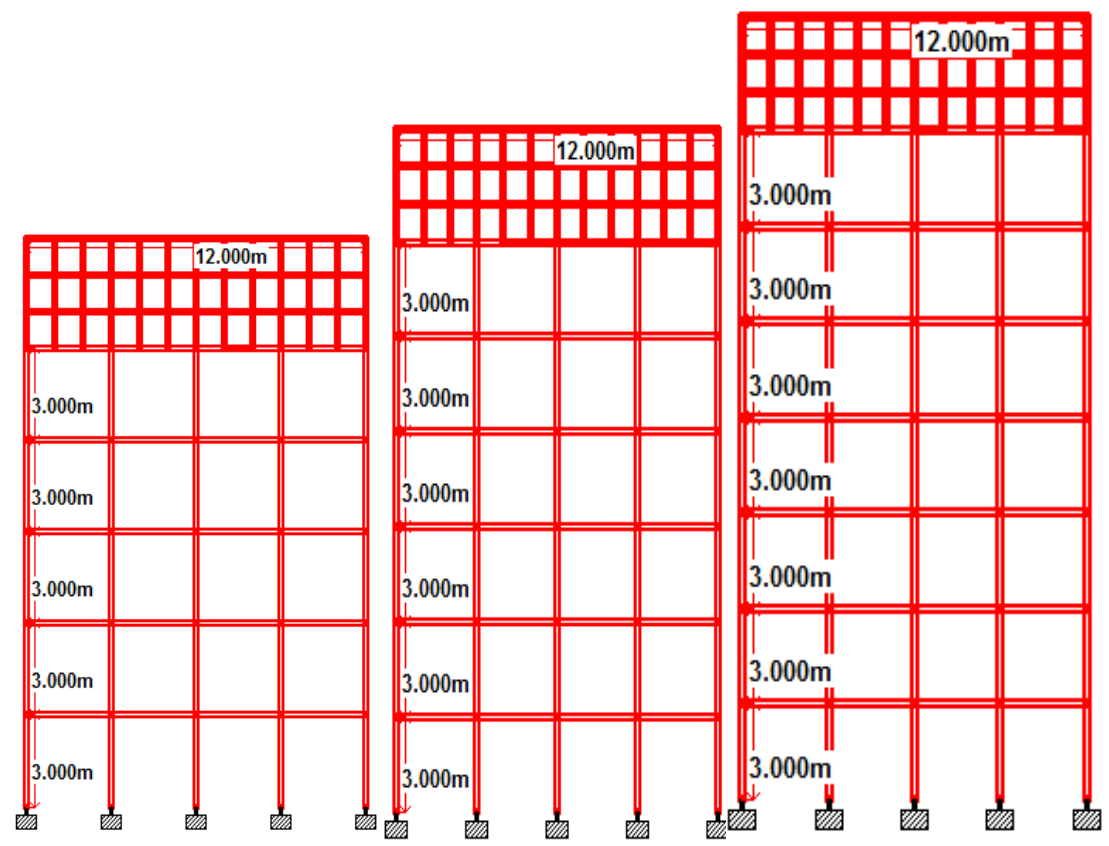

Fig. 2:-Elevation of Different Staging Height of Water Tank

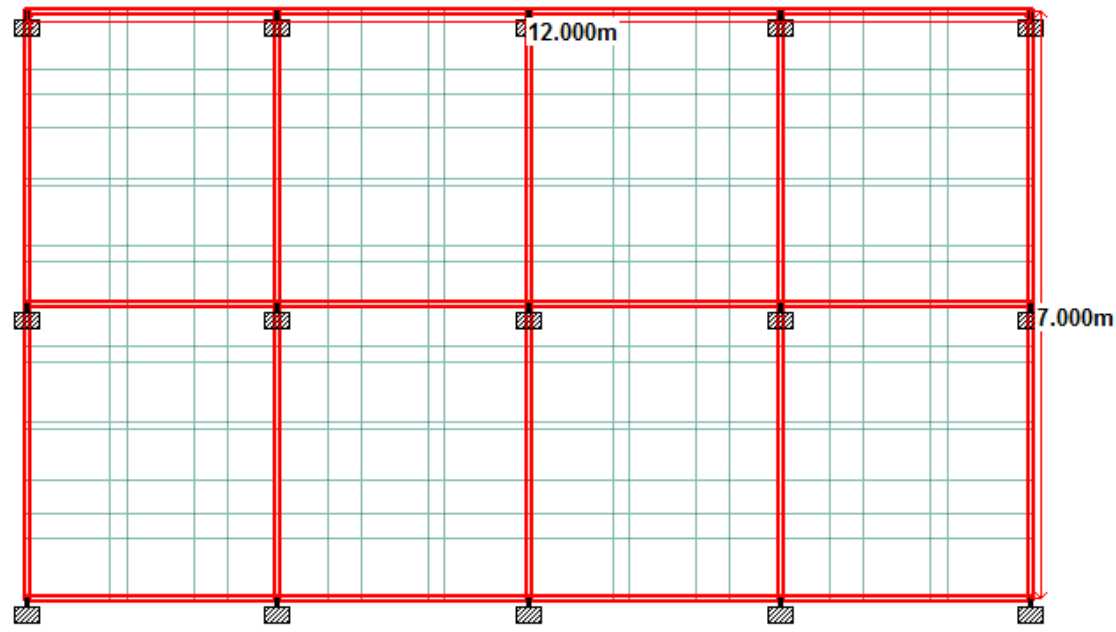

Fig. 3:-Plan of Water Tank

\section{Analysis:-}

Seismic coefficient analysis or equivalent static analysis was carried out and found out the response of the R.C elevated rectangular tank on the above models as shown before. The calculation procedure two spring mass models for every model are considered as per IS 1893( part 2):2006 draft code.And response of the elevated water tank (base shear, overturning moment and displacement) is summarized below. Comparison between each of the following models are made based on analysis results and plotted in graphical format.

For analysis of this studying were used STAAD.pro and Excel sheets, to find out the value of maximum base shear and overturning moment used Excel sheet as per IS 1893(part 2):2006 draft code according the mentioned code two model masses model was made. Liquid mass is divided into two parts such as impulsive and convective mass.Analysis carried out and the value of maximum base shear and over turning moment were found out and plotted in the graphs. But for finding out the value of displacement was used the STAAD.pro package and found out the maximum displacement at the top of the water tank. 
TABLE.2:-Maximum Base Shear, Overturning Moment Displacement, Concrete Quantity and Steel Quantity

\begin{tabular}{|c|c|c|c|c|c|c|c|c|c|c|}
\hline Zone & $\begin{array}{l}\text { Height } \\
\text { (m) }\end{array}$ & $\begin{array}{l}\text { Width } \\
(\mathrm{m})\end{array}$ & $\begin{array}{l}\text { Ratio } \\
\text { L/B }\end{array}$ & $\begin{array}{l}\text { Length } \\
\text { (m) }\end{array}$ & $\begin{array}{l}\text { Staging } \\
\text { (m) }\end{array}$ & $\begin{array}{c}\text { MaxBase } \\
\text { Shear(KN) }\end{array}$ & $\begin{array}{l}\text { Max Moment } \\
\text { (KN.M) }\end{array}$ & $\begin{array}{l}\text { Displacement } \\
(\mathrm{mm})\end{array}$ & $\begin{array}{l}\text { Concrete } \\
\text { (m3) }\end{array}$ & $\begin{array}{l}\text { Steel } \\
(\mathrm{Kg})\end{array}$ \\
\hline \multirow{6}{*}{ II } & \multirow{24}{*}{3.6} & \multirow{24}{*}{7} & \multirow{24}{*}{1.3} & \multirow{24}{*}{12} & 6 & 388 & 8250 & 1.874 & 157.2 & 77302 \\
\hline & & & & & 9 & 424 & 8994 & 3.034 & 221.6 & 110091 \\
\hline & & & & & 12 & 459 & 9738 & 4.653 & 286 & 142879 \\
\hline & & & & & 15 & 495 & 10483 & 6.754 & 350.4 & 173936 \\
\hline & & & & & 18 & 530 & 11227 & 8.641 & 414.8 & 204751 \\
\hline & & & & & 21 & 565 & 11972 & 10.173 & 479.2 & 238191 \\
\hline \multirow{6}{*}{ III } & & & & & 6 & 621 & 13291 & 2.527 & 157.2 & 77302 \\
\hline & & & & & 9 & 678 & 14391 & 4.383 & 221.6 & 110480 \\
\hline & & & & & 12 & 735 & 15582 & 6.973 & 286 & 151936 \\
\hline & & & & & 15 & 791 & 16773 & 10.335 & 350.4 & 190740 \\
\hline & & & & & 18 & 848 & 17964 & 13.335 & 414.8 & 224895 \\
\hline & & & & & 21 & 905 & 19150 & 15.805 & 479.2 & 260340 \\
\hline \multirow{6}{*}{ IV } & & & & & 6 & 932 & 19801 & 3.390 & 157.2 & 78223 \\
\hline & & & & & 9 & 1017 & 21587 & 6.181 & 221.6 & 121183 \\
\hline & & & & & 12 & 1102 & 23373 & 10.067 & 286 & 159901 \\
\hline & & & & & 15 & 1187 & 25159 & 15.11 & 350.4 & 206616 \\
\hline & & & & & 18 & 1272 & 26946 & 19.64 & 414.8 & 254768 \\
\hline & & & & & 21 & 1357 & 28732 & 23.315 & 479.2 & 298164 \\
\hline \multirow{6}{*}{ V } & & & & & 6 & 1398 & 29701 & 4.705 & 157.2 & 84511 \\
\hline & & & & & 9 & 1526 & 32380 & 8.879 & 221.6 & 131217 \\
\hline & & & & & 12 & 1653 & 35060 & 14.708 & 286 & 185833 \\
\hline & & & & & 15 & 1781 & 37739 & 22.272 & 350.4 & 257231 \\
\hline & & & & & 18 & 1908 & 40419 & 29.067 & 414.8 & 318211 \\
\hline & & & & & 21 & 2036 & 43098 & 34.579 & 479.2 & 377731 \\
\hline
\end{tabular}

\section{Results and Discussion:-}

Maximum base shear, overturning moment and displacement with seismic coefficient static analysis are presented in the graphs as following they are observed that maximum base shear, overturning moment and displacement increase as staging height and seismic zones is increased.

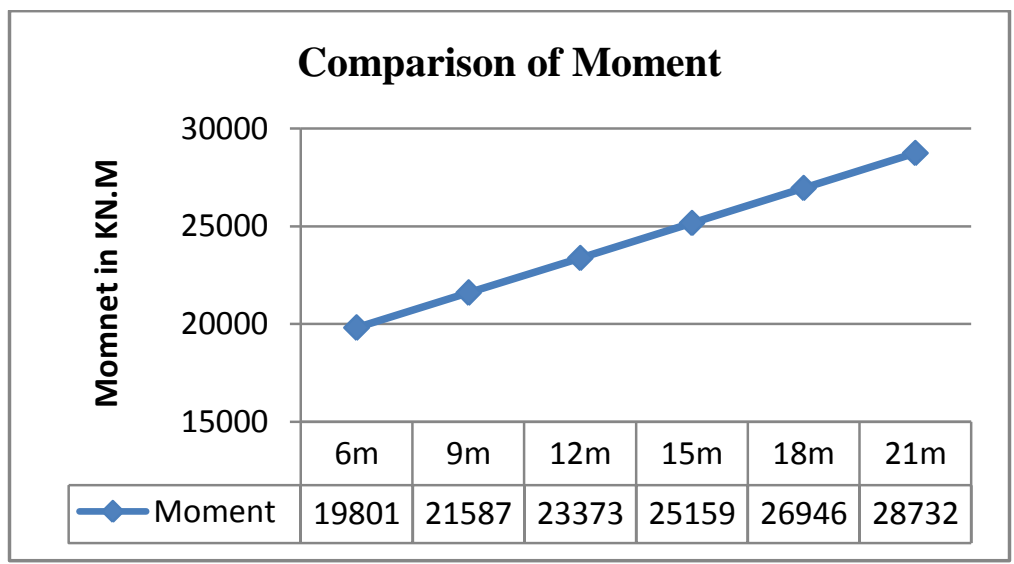

GRAPH1:- Variation of Moment in IV Seismic Zone and Different Staging Height

As theabove graph is plotted as shown there is a gradual increased overturning moment as increase the staging height in IV seismic zone. 


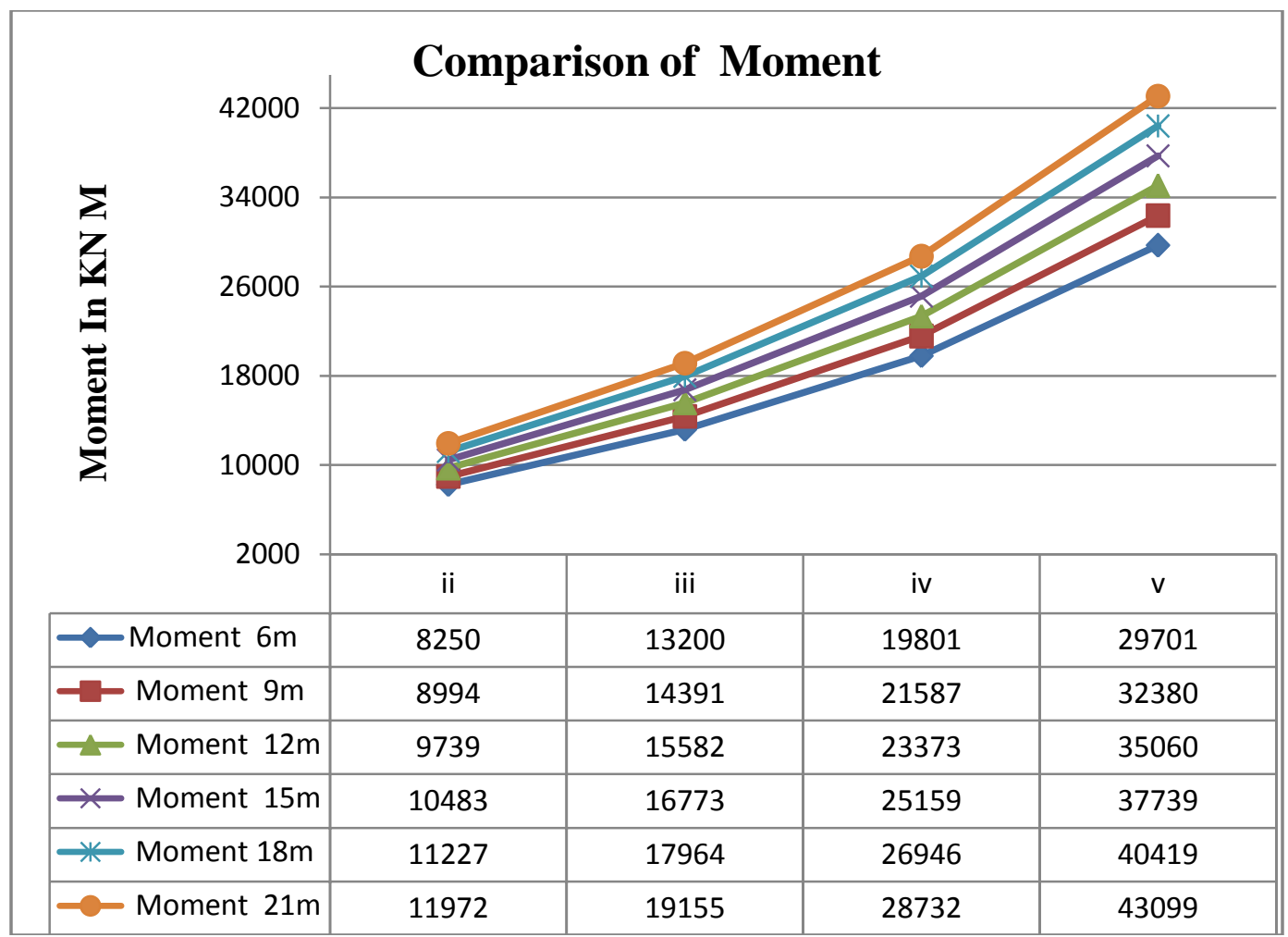

GRAPH2:- Variation of Moment in Different Sesimic Zones and Staging Height

As the above graph is plotted as shown there is a gradual increased the moment as increase in the different seismic zones. Also when the seismic zones are increased the values of moments between two staging heightsare increased.

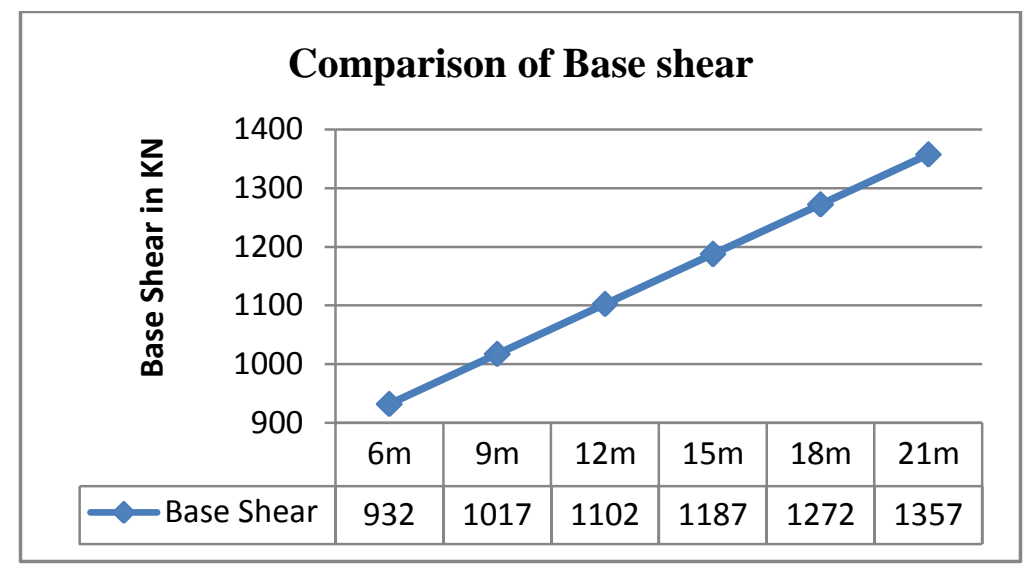

GRAPH3:- Variation of Base Shear in IV Seismic Zoneand Different Staging Height

As the above graph is plotted shows there is a gradual increased base shear as increase the staging height in IV seismic zone. 


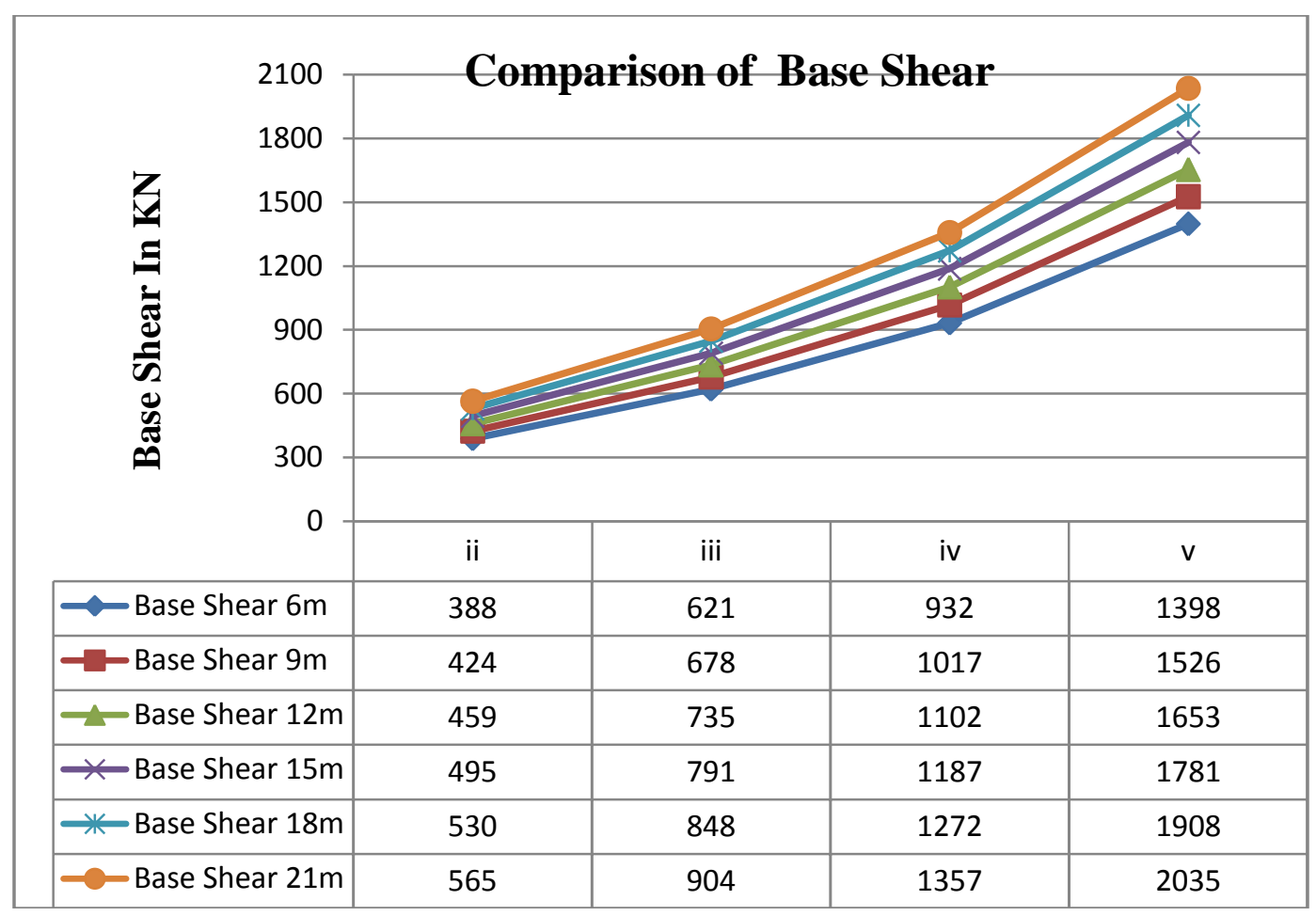

GRAPH4:- Variation of Base Shear in Different Seismic Zones and Staging Height

As the above graph is plotted shows there is a gradual increased the base shear as increase staging height in the different seismic zones. Also when the seismic zones are increased the values of base shear between two staging heights are increased.

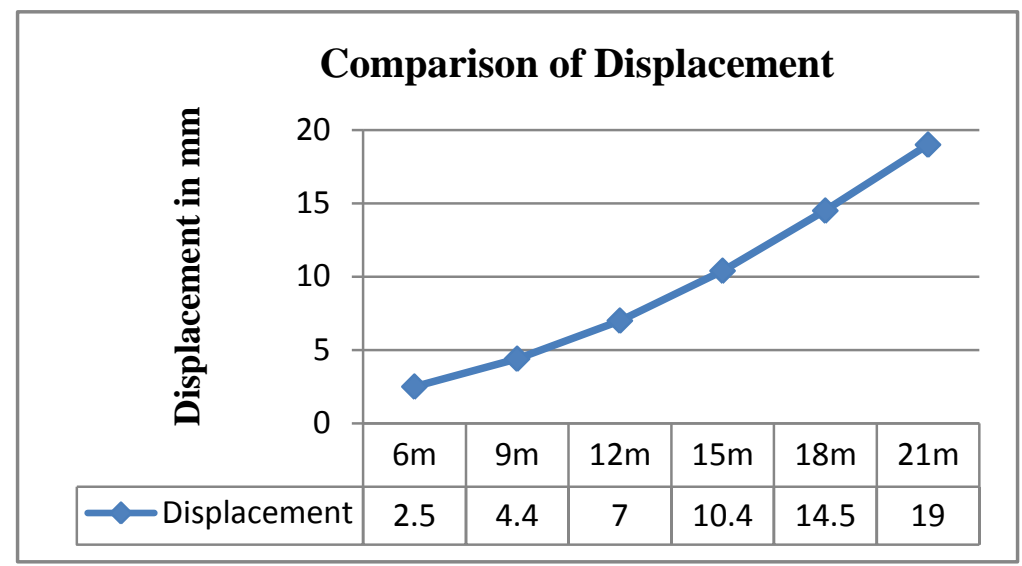

GRAPH5:- Variation of Displacement in IV Seismic Zoneand Different Staging Height

As the above graph is plotted shows there is a gradual increased displacement as increase the staging height in IV seismic zone. Displacement shows the requirement of enough columns and sufficient supporting system. 


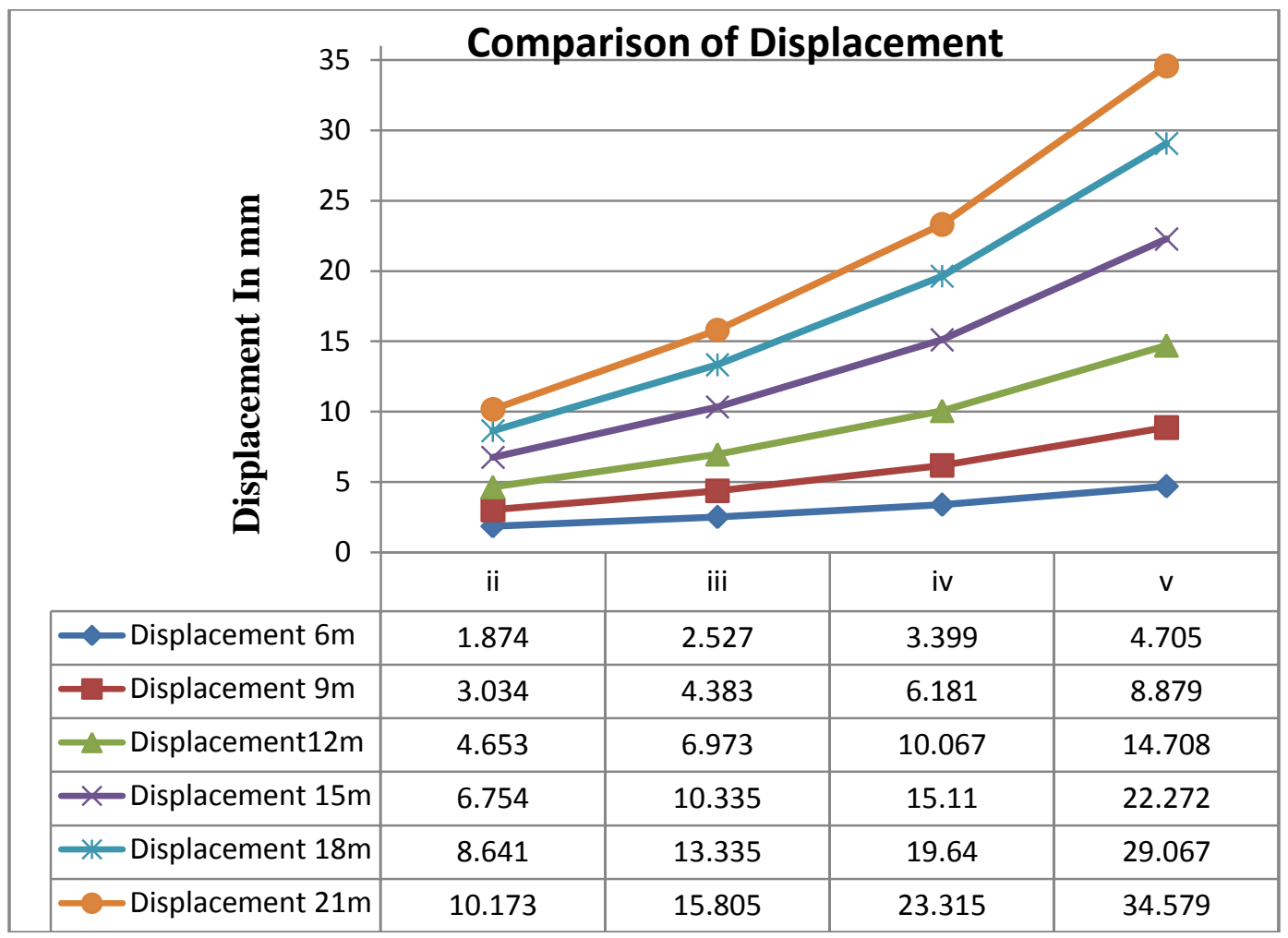

GRAPH6:- Variation of Horizontal Displacement in Different Seismic Zones and Staging Height

As theabove graph is plotted shows there is a gradual increase in the displacement as increase in the different seismic zones.by increasing the height of the staging the displacement increase this value shows when increasing the staging height the column and supporting system need more and these columns and supporting systems are not sufficient.

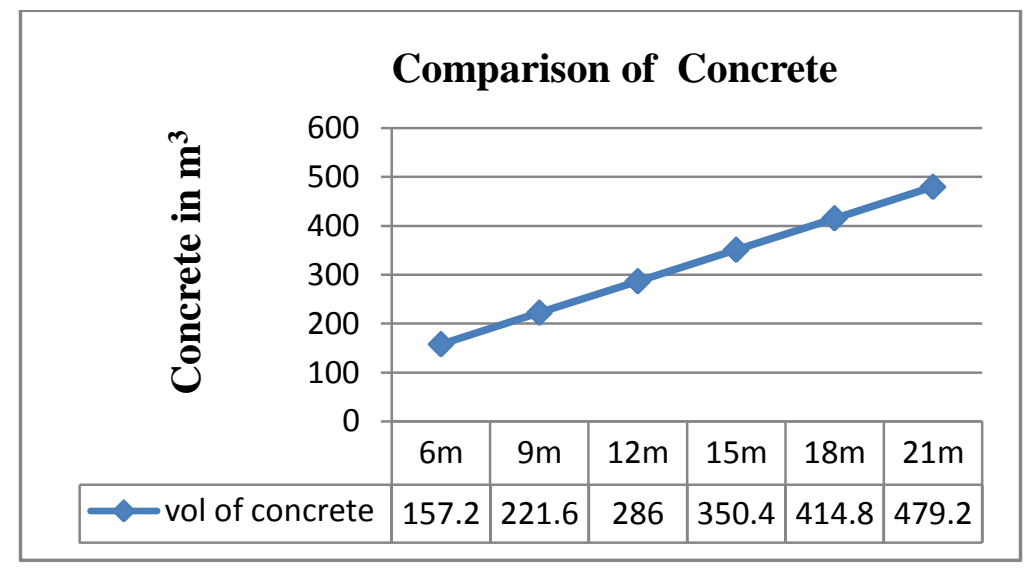

GRAPH 7:- Variation of Concrete Quantity inIV Seismic Zone and Different Stagin Height

As theabove graph is plotted isshown there is a gradual increased quantity of concrete as increase the staging height in IV seismic zone. 


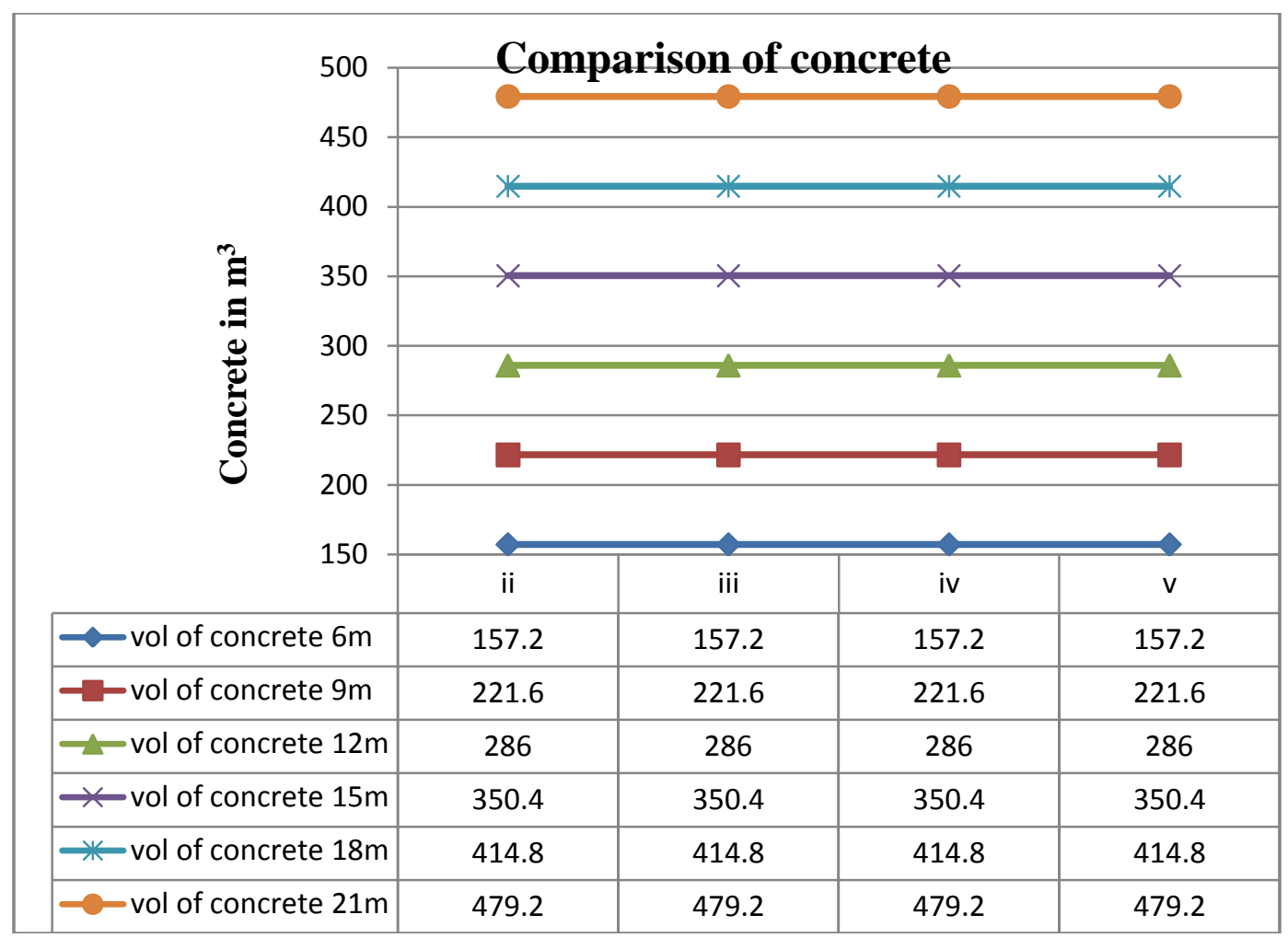

GRAPH 8:- Variation of Concrete Quantity in Different Seismic Zones and Staging Height

As theabove graph is plotted is shown the concrete quantity is remained constant, while the seismic zones are increased because the cross section of the structure is not changed.

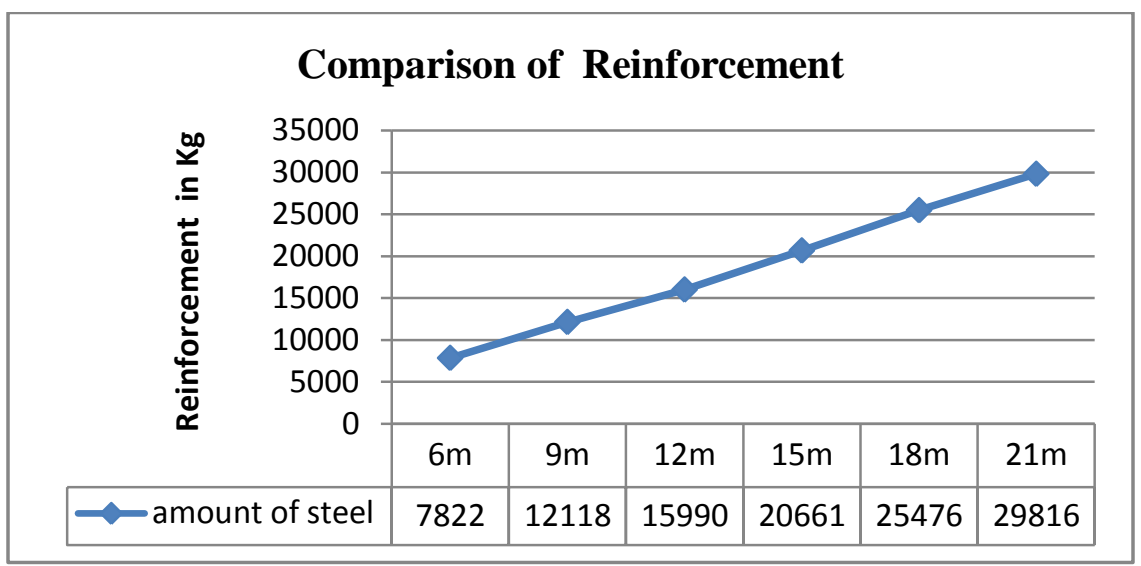

GRAPH 9:-Variation of Displacement inIV Seismic Zone and Different Staging Height

As theabove graph is plotted shows there is a gradual increasedquantity of steel is increased the staging height in IV seismic zone. 


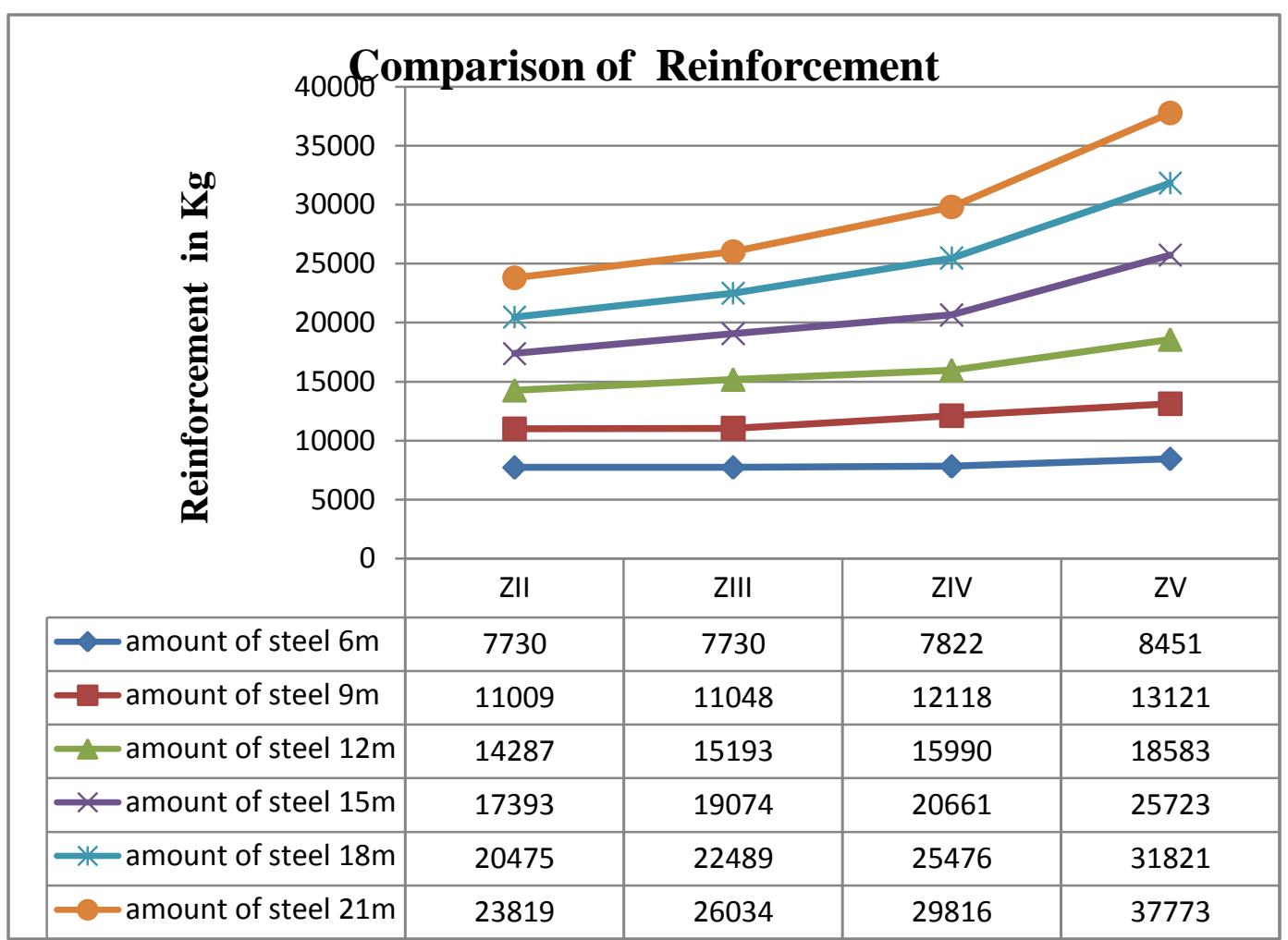

GRAPH10:- Variation of Steel Quantity in Different Seismic Zones and Staging Height

As per the abovegraph is plotted shows there is a gradual increased in the quantity of reinforcement as increase the different seismic zones.by increasing the staging height the amount of steel is increased. Because we did not changed the cross section of the structure therefore the earthquake forces also undergo by reinforcement.

\section{Conclusion:-}

The elevated water tank has $300 \mathrm{~m}^{3}$ capacity, various staging height such as $(6 \mathrm{~m}, 9 \mathrm{~m}, 12 \mathrm{~m}, 15 \mathrm{~m}, 18 \mathrm{~m}$ and $21 \mathrm{~m})$ and also considered in different seismic zones such as II, III, IV \& V were studied in STAAD.pro analysis package and Excel sheet developed program. The spring mass model issubjected totwo degrees of freedom system as per IS 1893 (part 2):2006 draft code. The conclusions are made as per comparing of the results:

1. Base shear, overturning moment and displacement are increased with increasing the staging height and seismic zones.Because when the structure height is increased the mass and distance between the center of gravity and ground level is increased as per IS 1893 (part 2) :2006.

2. The values of the base shear and overturning moment are slightly become more. And also when the structure height becomes more the displacement valuesare proportional becoming more, because the structurecomes flexible and displacementvalue shows the requirement of columns and sufficient supporting system.

3. Values of maximum base shear, maximum overturning moment and maximum horizontal displacement have been shown the Response of elevated water tank.

4. In the case of studying seismic zones such as II, III, IV and Vare changed, the geometry of structure is remained constant therefore the quantity of concrete is not changed, but the reinforcement quantity is increased due to increasing seismic zones. Software able to provide the requirement of reinforcement to resist the seismic forces without any changing of the cross section. 


\section{References:-}

1. Layout of Overhead Tanks "Indian Standard Criteria For design of RCC Staging for Overhead Water Tanks"(First Reprint October 1998),Is:11992-1995(Reaffirmed 2003)

2. Codal of Water Tanks "Criteria for Earthquake Resistant Design of Strucutres: Part 2 Liquid Retaining Tanks,(Revision of Is 1893(Part 2))"(First Reprint October 1998 ), Is: 11992-1995( Reaffirmed 2003)

3. Sudhir K Jain*and O. R. Jaiswal "Modified Proposed Provisions for Aseismic Design of Liquid Storage Tanks: Part I - Codal Provisions"Journal of Structural Engineering- Vol. 32, No.3, August-September 2005 Pp. 195206.

4. S. Bozorgmehrnia1*, M.M. Ranjbar2 and R. Madandoust2 "Seismic Behavior Assessment of Concrete Elevated Water Tanks" Journal of Rehabilitation In Civil Engineering 1-2 (2013) 69-79.

5. F. Omidinasab* and H. Shakib** "Seismic Response Evaluation of the R.C Elevated Water Tank with FluidStructure Interaction and Earthquake Ensemble"Ksce Journal of Civil Engineering (2012) 16(3):366-376

6. Uma Chaduvula, Deepam Patela, N Gopalakrishnanb "Fluid-Structure-Soil Interaction Effects on Seismic Behaviour of Elevated Water Tanks" Procedia Engineering 51 (2013) 84 - 91

7. Assist. Prof. Dr. Kamila Kotrasová1assoc. Prof. Dr. Eva Kormaníková2

8. Assoc. Prof. Dr. Ioan Sorin Leoveanu3 “Seismic Analysis of Elevated Reservoirs"Research Gate Conference Paper · January 2013

9. Ramazan Livaoğlu1 and Adem Doğangün2 "Dynamic Behavior and Seismic Performance of Elevated Tanks Due To Ground Types Defined In Ec-8 and Tec-06"First European Conference on Earthquake Engineering and Seismology.

10. Albert T. Y. Tung' and Anne S. Kiremidjian, 2 Member "Seismic Reliability Analysis of Elevated LiquidStorage Vessels", ASCE.

11. Medhat A. Haroun and Wajdi Abou-Lzzeddine. "Parametric Study of Seismic Soil-Tank Interaction. I: Horizontal Excitation"ASCE,

12. Mostafa Masoudi A,B, Sassan Eshghi B, Mohsen Ghafory-Ashtiany B. "Evaluation of Response Modification Factor (R) of Elevated Concrete Tanks", Engineering Structures 39 (2012) 199-209,

13. M. Moslemia, M.R. Kianoush A, W. Pogorzelski B. "Seismic Response of Liquid-Filled Elevated Tanks" , Engineering Structures 33 (2011) 2074-2084,

14. Design of Water Tanks "Reinforced Concrete Vol.II (Advanced Reinforced Concrete)" Dr.H.J.Shah.

15. Design of Elevated Rectangular Water Tank "Arthur H. Nilson: Design

16. Earth Quake Calculation For The Tank Supported on The Frame "Criteria For Earthquake Resistant Design of Strucutres: Part 2 Liquid Retaining Tanks, (Revision of IS 1893(Part 2))" (First Reprint October 1998), IS: 11992-1995( Reaffirmed 2003). 